\title{
Comparison of the 235 ribosomal RNA genes and the spacer region between the 165 and 235 rRNA genes of the closely related Mycobacterium avium and Mycobacterium paratuberculosis and the fast-growing Mycobacterium phlei
}

\author{
Johanna W. B. van der Giessen, René M. Haring \\ and Bernard A. M. van der Zeijst
}

Author for correspondence: B. A. M. van der Zeijst. Tel: +3130 534344. Fax: +3130540784.

Department of Bacteriology, Institute of Infectious Diseases and Immunology, School of Veterinary Medicine, Utrecht University, PO Box 80.165 , 3508 TD Utrecht, The Netherlands
The 235 rDNA sequences of Mycobacterium paratuberculosis, $M$. avium and $M$. phlei and the sequences of the spacer regions between the 16S and 235 rRNA genes were determined. The overall 235 rDNA sequence identity between $M$. paratuberculosis and $M$. avium was $99.7 \%$ (nine mismatches), showing the very close relatedness of these mycobacteria. Evolutionary distances between the five known mycobacterial 235 rRNA/rDNA sequences and those of other Gram-positive $G+C$-rich bacteria were determined. The 235 rDNA sequences of mycobacteria showed two inserted regions compared to the other bacteria. A mycobacterial unique region contained one mismatch between $M$. paratuberculosis and $M$. avium. An Actinomycetales-specific insertion, consisting of 111 nucleotides, was completely identical for $M$. paratuberculosis and $M$. avium. The sequence of the intergenic spacer region between $16 \mathrm{~S}$ and 235 rDNA had a length of $\mathbf{2 7 8}$ bp for $M$. paratuberculosis and $M$. avium with only two mismatches. The spacer region of the fast-growing $M$. phlei was 85 bp longer. No tRNA-encoding region was found in the spacer region.

Keywords: $23 \mathrm{~S}$ rRNA gene, intergenic spacer region, mycobacteria

\section{INTRODUCTION}

Mycobacterium avium and $M$. intracellulare, members of the M. avium complex (MAC), are important opportunistic pathogens in humans. Infections with these bacteria have become a major problem in immunodeficient people, especially in AIDS patients (Armstrong, 1985). $M$. paratuberculosis is the causative agent of paratuberculosis, an economically important intestinal disease of ruminants and it is also associated with Crohn's disease in humans (Chiodini, 1989). M. paratuberculosis has been included in the MAC, because of the close relatedness with the mycobactin-dependent $M$. avium strains (Mathews \& McDiarmid, 1979; Hurley et al., 1988; McFadden et al., 1992; Thorel et al., 1990).

Mycobacteria may be divided in four groups, based on growth rate and pigmentation (Runyon et al., 1974). Further taxonomic classification of mycobacteria is complicated, because of the variety of specialized tests needed.
The comparison of ribosomal RNA (rRNA) sequences or the genes encoding rRNA ( $\mathrm{rDNA}$ ) has proved to be a powerful tool for the phylogenetic classification of bacteria (Woese, 1977). Phylogenetic studies based on the analysis of $16 \mathrm{~S}$ rRNA of mycobacteria confirmed the classical division in fast- and slow-growers (Stahl \& Urbance, 1990). However, in those cases where the $16 \mathrm{~S}$ rRNA sequences of closely related species are almost identical, these sequences are not sufficient for phylogenetic analysis (Fox et al., 1992). For instance, the 16S rRNA sequences of $M$. paratuberculosis and $M$. avium are 99.9\% identical (Stahl \& Urbance, 1990; Rogall et al., 1990). Species-specific probes for M. paratuberculosis based on the $16 \mathrm{~S}$ rRNA sequence could not be derived, because of the high level of $16 \mathrm{~S}$ rRNA sequence identity with $M$. avium (Van der Giessen et al., 1992).

Recently, the sequence of the gene coding for the large $23 \mathrm{~S}$ rRNA subunit of $M$. leprae was determined (Liesack et al., 1991). Comparison with selected regions of the $23 \mathrm{~S}$ 
rRNA of other mycobacterial species showed that a $M$. leprae-specific probe could be developed. Further, sequence analysis of the intergenic spacer region between the $16 \mathrm{~S}$ and $23 \mathrm{~S}$ rRNA subunit genes showed a high degree of variability even between closely related species (Suzuki et al., 1988; Liesack et al., 1991).

We present sequences of the genes encoding the $23 \mathrm{~S}$ rRNA of $M$. avium, $M$. paratuberculosis and $M$. pblei including the sequences of the intergenic spacer regions. These sequences were compared with previously determined 23S rRNA sequences of bacteria stored in the EMBL database, in particular $M$. leprae, other Grampositive, $\mathrm{G}+\mathrm{C}$ rich actinomycetes, B. stearothermopibilus and two Gram-negative bacteria (Gutell et al., 1992). Our aim was to compare the $23 \mathrm{~S}$ rDNA sequences of the closely related $M$. avium and $M$. paratuberculosis and to examine the possibility of deriving species-specific oligonucleotide probes for $M$. paratuberculosis.

\section{METHODS}

Bacterial strains and DNA extraction. DNA was extracted from $M$. avium strain 23435 serotype 8 (Institute Pasteur, Paris), $M$. paratuberculosis strain J2A (CVL, Weybridge), $M$. pblei strain R82 (CVL, Weybridge), M. fortuitum (CVI, Lelystad) and $M$. chelonei (CVI, Lelystad) as described by Van der Giessen et al. (1992).

Polymerase chain reaction and cloning of the 23S rDNA gene and the intergenic spacer region. The $23 \mathrm{~S} \mathrm{rDNA}$ genes of the mycobacteria were amplified in three parts. Part 1 was amplified with primers P1 [5'-GAT(G/T)TCCGAATGGG(C/G)AACCC-3'] position 109-129 and P2 (5'-GACCAGTGAGCTATTACGC-3') position 1193-1211 of the $M$. avium/ paratuberculosis 23S rDNA sequence. Part 2 was amplified with primers P3 (5'-GGCTTAGAAGCAGCCATCC-3') position 1164-1182 and P4 (5'-GGTCGGAACTTACCCGAC-3') position 2153-2170. Part 3 was amplified with primers P5 (5'GTCGGGTAAGTTCCGACC-3') position $2153-2170$ and P7 (5'-GCTTTCGGCCAGTTAGTGCCAG-3') position 30793100. The intergenic region was amplified with primers I1 (' $5^{\prime}-$ TGCGGTGGATCACC'TCCT'T-3') position 1522-1541 of the $16 \mathrm{~S}$ rRNA gene and 12 (5'-GGTTCCCCCATTCGGAAATC$\left.3^{\prime}\right)$ position 109-128 of the $23 \mathrm{~S}$ rRNA gene. Conditions of the PCR were: 35 cycles $\left(1 \mathrm{~min}, 95^{\circ} \mathrm{C} ; 2 \mathrm{~min}, 58^{\circ} \mathrm{C} ; 3 \mathrm{~min}, 72^{\circ} \mathrm{C}\right)$; total volume $100 \mu \mathrm{l}$ containing $100 \mathrm{ng}$ template DNA, $200 \mathrm{mM}$ $\mathrm{KCl}, 10 \mathrm{mM}$ Tris $/ \mathrm{HCl}$ ( $\mathrm{pH} \mathrm{8.3),} 1.5 \mathrm{mM} \mathrm{MgCl}_{2}$, gelatin $0 \cdot 1 \mathrm{~g} \mathrm{l}^{-1}, 200 \mu \mathrm{M} \mathrm{dNTP}, 1 \mu \mathrm{M}$ of both primers and $2 \cdot 5$ Units of Taq polymerase (Promega), covered with $100 \mu \mathrm{l}$ paraffin oil. PCR products of part 1 were inserted in PstI-digested poly-Gtailed vector pUC19 (Pharmacia-LKB). PCR products of parts 2, 3 and the intergenic region were ethanol-precipitated, made blunt by incubation with Klenow fragment of DNA polymerase I and $1.67 \mathrm{mM}$ dNTP and ligated into EcoRV-digested vector Bluescript KS M13 - (pBS, Stratagene). Plasmid vectors were electroporated and propagated in E. coli K12 strain PC2495, a $\operatorname{rec} A^{-}$derivative of JM101 (Yanisch-Perron et al., 1985).

Sequencing of the intergenic spacer region and the 235 rDNA genes. Plasmid DNAs were isolated using the Qiagen plasmid kit according to the manufacturer's manual. The sequence of the cloned $23 \mathrm{~S} \mathrm{rDNA}$ was determined by using the dideoxy chain termination method (Sanger et al., 1977), an automated laser fluorescent DNA sequencer (Pharmacia) and the autoread sequencing kit using T7 DNA polymerase (Pharmacia). Besides the fluorescein isothiocyanate (FITC)-labelled universal sequence primers (5'-CCCTCGAGGTCGACGGTATCG- ${ }^{\prime}$ and $5^{\prime}$-GCCGCTCTAGAACTAGTGGATC-3') the following FITC-labelled internal primers were used to determine the $23 \mathrm{~S}$ rDNA sequences. S1 (5'-AGTAGCGGCGAGCGAA-3') position 245-260; S2 (5'-TAGCTGGTTCTCCCCGAAA-3') position 948-956; S5 (5'-GGAGTGAGGAATGCAGGCATG$\left.3^{\prime}\right)$ position 1408-1427; S6 (5'-GGGGCTGCGTGGGACC-3') position 1657-1672; S7 (5'-CCCCAAACCAACACAGGTGG$\left.3^{\prime}\right)$ position 1886-1905; S8 (5'-AACTGGGGCGGTTGCTCC$\left.3^{\prime}\right)$ position 2543-2561 of the $23 \mathrm{~S}$ rDNA sequence compared to E. coli.

Data analysis. Sequences were aligned using pILEup and CLUSTALv computer programs (Devereux et al., 1984; Higgins \& Sharp, 1988). Phylogenetic analyses were performed with distance matrix and maximum parsimony methods, as described in the Felsenstein-Phylip package version 3.3 (Felsenstein, 1985). Phylogenetic trees were made with data distance matrix FITCH (Fitch \& Margoliash, 1967), NJTree (Saitou \& Nei, 1987), UPGMA (Sneath \& Sokal, 1973), and кITCH (Fitch \& Margoliash, 1967) phylogenetic computer programs.

The $23 \mathrm{~S}$ rRNA/rDNA sequences of $M$. leprae, $M$. kansasii, Micrococcus luteus, Streptomyces griseus, Streptomyces ambofaciens, Bacillus stearothermophilus, Frankia sp., Pseudomonas aeruginosa and E. coli were derived from the EMBL and GenBank databases.

\section{RESULTS AND DISCUSSION}

The determined sequences of $23 \mathrm{~S}$ rDNA of $M$. paratuberculosis and $M$. avium have a length of $3100 \mathrm{bp}$ and are thus only slightly shorter than the $23 \mathrm{~S} \mathrm{rDNA}$ gene of $M$. leprae (3122 bp) (Liesack et al., 1991) and M. phlei (3121 bp). The sequences were submitted to the EMBL. Data Library and will be available under the accession numbers X74495, X74494 and X74493, respectively.

The $23 \mathrm{~S}$ rDNA sequences and their intergenic spacer regions between the $16 \mathrm{~S}$ and $23 \mathrm{~S}$ rDNA of $M$. avium serotype $8, M$. paratuberculosis $\mathrm{J} 2 \mathrm{~A}$ and $M$. phlei were determined in order to examine the possibility of deriving species-specific DNA probes for $M$. paratuberculosis. $M$. avium serotype 8 strain was sequenced because this is one of the serotypes which is indistinguishable from $M$. paratuberculosis based on 16S rRNA analysis (Böddinghaus et al., 1990). The alignment of the 23S rDNA mycobacterial sequences and the $23 \mathrm{~S} \mathrm{rRNA} / \mathrm{rDNA}$ sequences of other Gram-positive bacteria with a high $\mathrm{G}+\mathrm{C}$ content revealed a high resemblance. Evolutionary distances of the $23 \mathrm{~S}$ rDNA sequences were generated by the distance matrix analysis and the FITCH program using the total length of 3200 nucleotides of the multiple sequence alignment (Table 1). Gaps were not considered in the calculations. Results obtained with the other programs were not significantly different from those of the FITCH program. The $23 \mathrm{~S} \mathrm{rDNA}$ sequences of $M$. avium and $M$. paratuberculosis were $99 \cdot 7 \%$ identical. A similar high level of identity was found in the 16S rRNA subunits (99.9\%) (Stahl \& Urbance, 1990; Rogall et al., 1990). However, when $23 \mathrm{~S}$ rDNA sequences of $M$. avium and $M$. paratuberculosis were compared to those of other mycobacteria, they appeared to be less similar than the $16 \mathrm{~S}$ rRNA/DNA sequences (Table 2). A tree of the clustering relations of 
Table 1. Evolutionary distances $(\times 100)$ based on the 235 rRNA genes of the Grampositive high-G + C-containing bacteria, and two Gram-negative bacteria, $P$. aeruginosa and $E$. coli

\begin{tabular}{|c|c|c|c|c|c|c|c|c|c|c|c|c|}
\hline & 1. & 2. & 3. & 4. & 5. & 6. & 7. & 8. & 9. & 10. & 11. & 12. \\
\hline 1. M. paratuberculosis & 0 & & & & & & & & & & & \\
\hline 2. M. avium & $0 \cdot 3$ & 0 & & & & & & & & & & \\
\hline 3. M. kansasii & $3 \cdot 8$ & $3 \cdot 7$ & 0 & & & & & & & & & \\
\hline 4. M. leprae & $4 \cdot 8$ & $4 \cdot 8$ & $4 \cdot 7$ & 0 & & & & & & & & \\
\hline 5. M. phlei & $8 \cdot 7$ & $8 \cdot 7$ & $8 \cdot 9$ & $10 \cdot 1$ & 0 & & & & & & & \\
\hline 6. Frankia sp. & $19 \cdot 9$ & $19 \cdot 9$ & $19 \cdot 9$ & $20 \cdot 5$ & $19 \cdot 4$ & 0 & & & & & & \\
\hline 7. S. ambofaciens & $20 \cdot 7$ & $20 \cdot 7$ & $20 \cdot 9$ & $21 \cdot 8$ & $20 \cdot 3$ & $14 \cdot 3$ & 0 & & & & & \\
\hline 8. S. griseus & $20 \cdot 4$ & $20 \cdot 3$ & $20 \cdot 4$ & $21 \cdot 2$ & $20 \cdot 3$ & $14 \cdot 1$ & $4 \cdot 5$ & 0 & & & & \\
\hline 9. Mic. luteus & $20 \cdot 1$ & $20 \cdot 1$ & $20 \cdot 0$ & $20 \cdot 2$ & $20 \cdot 8$ & $19 \cdot 2$ & $18 \cdot 3$ & $18 \cdot 2$ & 0 & & & \\
\hline 10. B. stearothermophilus & $30 \cdot 8$ & $30 \cdot 9$ & $30 \cdot 8$ & $30 \cdot 8$ & $30 \cdot 9$ & $28 \cdot 5$ & $30 \cdot 9$ & $31 \cdot 3$ & $32 \cdot 3$ & 0 & & \\
\hline 11. P. aeruginosa & $37 \cdot 2$ & $37 \cdot 2$ & $37 \cdot 0$ & $36 \cdot 7$ & $36 \cdot 8$ & $34 \cdot 3$ & $35 \cdot 8$ & $36 \cdot 5$ & $37 \cdot 3$ & $30 \cdot 7$ & 0 & \\
\hline 12. E. coli & $38 \cdot 9$ & $38 \cdot 9$ & $39 \cdot 1$ & $39 \cdot 6$ & $39 \cdot 6$ & $38 \cdot 2$ & $38 \cdot 6$ & $38 \cdot 7$ & $36 \cdot 7$ & $34 \cdot 5$ & $17 \cdot 5$ & 0 \\
\hline
\end{tabular}

Table 2. Percentage identity of mycobacteria based on the 165 rRNA sequences (top right) (Stahl \& Urbance, 1990 ) and the 235 rDNA sequences (lower left)

\begin{tabular}{|lccccc|}
\hline & 1. & 2. & 3. & 4. & 5. \\
\hline 1. M. paratuberculosis & 0 & $99 \cdot 9$ & $98 \cdot 1$ & $97 \cdot 2$ & $95 \cdot 3$ \\
2. M. avium & $99 \cdot 7$ & 0 & $98 \cdot 3$ & $97 \cdot 1$ & $95 \cdot 4$ \\
3. M. kansasii & $96 \cdot 2$ & $96 \cdot 3$ & 0 & $96 \cdot 7$ & $95 \cdot 3$ \\
4. M. leprae* & $95 \cdot 2$ & $95 \cdot 2$ & $95 \cdot 3$ & 0 & $94 \cdot 2$ \\
5. M. phlei & $91 \cdot 3$ & $91 \cdot 3$ & $91 \cdot 1$ & $89 \cdot 9$ & 0 \\
\hline
\end{tabular}

* 16S rRNA sequence (accession no. M61681) identity determined by using the FITCH computer program (Fitch \& Margoliash, 1967).

the $23 \mathrm{~S}$ rRNA/rDNA sequences constructed using the PILEUP computer program showed the close relatedness of $M$. paratuberculosis and $M$. avium (Fig. 1).

A unique insertion sequence in the $23 \mathrm{~S} \mathrm{rDNA}$ gene observed in some mycobacteria (Liesack et al., 1991) was also detected in $M$. paratuberculosis, $M$. avium and $M$. phlei at position $766-787$ of the multiple sequence alignment (Fig. 2). This sequence differed between the mycobacterial species; there was one mismatch between $M$. paratuberculosis and $M$. avium (Fig. 2). In the secondary structure model (Höpfl et al., 1989), the insertion is located between helices 27 and 31 (Liesack et al., 1991). The predicted secondary structure for the insertion sequence in $M$. paratuberculosis, $M$. avium and $M$. phlei is depicted in Fig. 3. The sequence of this region might be used to derive specific oligonucleotide probes, which can distinguish closely related species.

Helix 54 of the $23 \mathrm{~S}$ rRNA/rDNA sequences of the -Actinomycetales is much longer than that of the $23 \mathrm{~S}$ rRNA/rDNA sequences of other bacteria (Roller et al., 1992), and has been proposed to be an ideal target for diagnostic probes and selective PCR primers (Stackebrandt et al., 1991). A specific $M$. leprae oligonucleotide

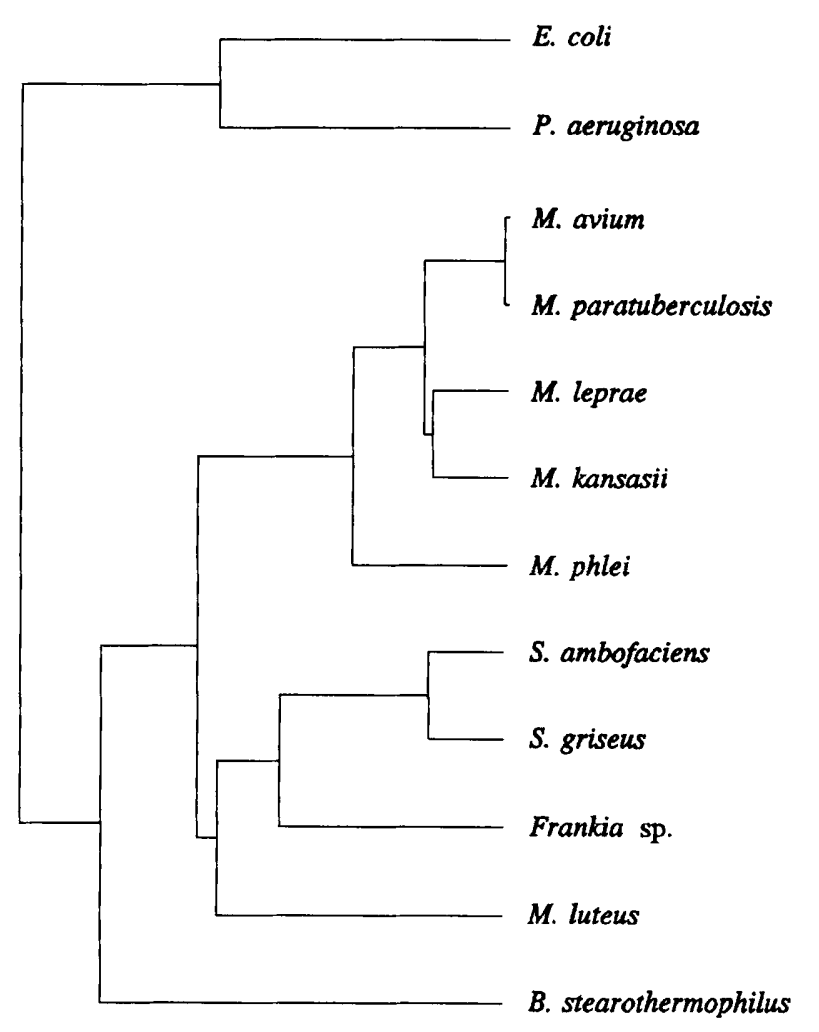

Fig. 1. Tree showing the clustering relations of the Grampositive G+C-rich bacteria, together with $B$. stearothermophilus, $E$. coli and $P$. aeruginosa using the PILEUP computer program.

probe was derived from this region (Liesack et al., 1991). Our data show that this extended helix is also present in the newly determined mycobacterial sequences. However, not a single mismatch was found between the inserted 111 nucleotides of $M$. paratuberculosis and $M$. avium (Fig. 4). This again stresses the close relatedness between $M$. paratuberculosis and $M$. avium. Only nine mismatches were observed between the complete $23 \mathrm{~S}$ rRNA genes. 
1. M. paratuberculosis

2. M. avium

3. M. kansasii

4. M. leprae

5. M. phlei

6. Frankia sp.

7. S. ambofaciens

8. S. griseus

9. M. luteus

10. B. stearothermophilus

11. P. aenuginosa

12. E. coli
751

800

AGTCIGAATA GGGCGCAT-- --CCCTITTG ---GGGTGTA GTGGCGTGTT AGTCTGAATA GGGCGCAT.- -. CCCCTTTG ---GGGTGTA GTGGCGIGIT AGTCTGAATA GGGCGTAT-- -- CGCGCGCG AGCGTGTGTA GIGGCGTGIT AGTCTGAATA GGGCGTAT-- -- CACGTGTG AGCGTGTGTA GTGGCGTGTT AGTCTGAATA GGGCGTATCC AACCTGTTGG GGTTGGTGTA GTGGTGTGTT AGTCCGAGGA GGGCG-.................. TTGA GTCGCATGTC AGTCCGAATA GGGCG-.................. AGTCCGAACA GGGCG-................... GTTGA GTTGCACGCT AGTCTGAATA GGGCG-.... AGTCTGAACA GGGCGAA-..................... GTACGTCGTC AGTCTTAATA GGGCG-................... TITA GTCGCTGGGT

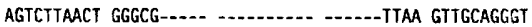

Fig. 2

$U^{U} U$
$C-G$
$C-G G$
$C--G$
$U .-G$
$A=-U$
$C=-G$
$G .$. UAGU
M. paratuberculosis

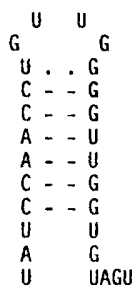

M. phlei

Fig. 3

Fig. 2. Unique mycobacterial insertion sequence of the 235 rDNA gene corresponding to position 762-784 of the multiple sequence alignment of the $23 \mathrm{~S}$ rDNA of $\mathrm{G}+\mathrm{C}$-rich bacteria, together with $E$. coli and $P$. aeruginosa. Dashes indicate gaps.

Fig. 3. Predicted secondary structure of the 235 rRNA sequences located between helices 27 and 31 of $M$. paratuberculosis, $M$. avium and $M$. phlei.

1. M. paratuberculosis
2. M. avium
3. M. kansasii
4. M. leprae
5. M. phlei
6. Frankia sp.
7. S. ambofaciens
8. S. griseus
9. M. luteus
10. B. stearothermophilus
11. P. aeruginosa
12. E. coli
1. M. paratuberculosis
2. M. avium
3. M. kansasii
4. M. leprae
5. M. phlei
6. Frankia sp.
7. S. ambofaciens
8. S. griseus
9. M. luteus
10. B. stearothermophilus
11. P. aenuginosa
12. E. coli
1. M. paratuberculosis
2. M. avium
3. M. kansasii
4. M. leprae
5. M. phlei
6. Frankia sp.
7. S. ambofaciens
8. S. griseus
9. M. luteus
10. B. stearothermophilus
11. P. aenginosa
12. E. coli

1.

1. M. paratuberculosis

M. avium

M. leprae

8. S. griseus

9. M. luteus

10. B. stearothermophilus

11. P. aeruginosa

1. M. paratuberculosis

2. M. avium

5. M. phlei

6. Frankia $\mathrm{sp}$

$S$ ambofaciens

9. M. luteu.

10. B. stearothermophilus

11. P. aenuginosa

uberculosis

M. leprae

8. S. griseus

11. P. aenuginose

1551

GGGTTGATAT TCCCGTACCC GTGTATGGGC GTCCCTGATG AATC-A-GCG GGGTTGATAI TCCCGTACCC GTGTATGGGC GTCCCTGATG AATC-A-GCG GGGTTGATAT TCCCGTACCC GTGTGTGGGC GCCCGTGATG AATC-A-GCG GGGTTGATAT TCCCGTACCC GTGTGTGTGC GCCCGTGATG AATC-A-GCO GGGTTGATAT TCCCGTACCC GTGTATGAGC GTCCCTGATG AATCTC-ATT GGGTTGATAT TCCCGTACCG GCGITGACGC GGCCATGCTG AACCTGGTTT CGGTTGATAT TCCGGTACCC GCTGTGAAGC GTCAAACATC GAGCATCGTG CGGTTGAIAT T-CGGTACCC GCTITGAAAC GCCCAGTACT GAATCAGGCG GgGtTGATAT TCCCGTACCA GTGAaGAACC GCCCATGCTG AGCC--GGTG AGGTTGAGAT TCCTGTACCA CCTCCTTCCC GT................. AGGTTAATAT TCCTGTACTT CTGGTTAC-. AGGTTAATAT TCCTGTACTT GGIGTTAC...........................

$1601 \quad 1650$ GTACTAACCA CCCAAAACCG GATCGACCAT -TCCCCTTCG GGGGC-GTGG GTACTAACCA CCCAAAACCG GATCGACCAT -TCCCCTTCG GGGGC-GTGG GTACTAACCA CCCAAAACCG GATCGATCA- CTCCCCTTCG GGGGC-GTGG GTACTCACCA CCCAAAACCG GATCGACCAT ATCCCCTTCG GGGGCTATGG CTGCTAACCA CCCAAAACCT GGCCGATCAT ----CCTTCG GGGG---TGA GTGCTAA--C CATCTGAICG GATGTGTCTC ITCGGAGGTG ------TGTTC ATGCTAAGGC CGTGAAGCCG CCCTGATCTC ITCGGAGTTG AGGGGAGIGG ATGCTAAGTC CGTGAAGCCG GCCCGATCTC ITCGGAGTTG AGGGTAGTGG ATACTAACCG CCCGAACCAT CCCGAACCTC GTCTTTGACG GGGTCGGTGA

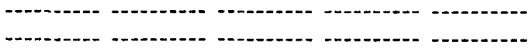

-

1651

1700

CGAIICGGGG CTGCGTGGGA CCTTCGCTGG TAGTAGTCAA GCAATGGGGT CGATTCGGGG CTGGGTGGGA CCITCGCTGG TAGTAGTCAA GCAATGGGGT AGGTCTGGGG CTGCGTGGAG CCTICGCTGG TAGTAGTCAA GCGATGGGGT AGGTICGGGG CTGCGTGGGA ACTTCGTTGG TAGTAGTCAA GCGATGGGGT CGGITGGGGG CIGCGTGGGA CC-CGGTGGG TAGTAGTCAA GCGATGGGGT GGGAGGGTGG GATCCCGGCT GGTAGTAGGC AAGC--G--- ---ATGGGGT TGGAGCCGCC GGACCAAGCG GTIAGTAGGT GAGT--G--- ---ATGGGGT TGGAGCCGAT GAACCAGACT TGTAGTAGGT AAGC--G-.- -.-ATGGGGT TGGGGAGCGC GGGACCTGAA CCGGGGAGGC AAGC--GCAT TAACAGGTGT

.

-

-

Fig. 4

M. paratuberculosis
M. avium
M. leprae
M. phlei
M. paratuberculosis
M. avium
M. leprae
M. phlei
M. paratuberculosis
M. avium
M. leprae
M. phlei
M. paratuberculosis
M. avium
M. leprae
M. phlei
M. paratuberculosis
M. avium
M. leprae
M. phlei

M. paratuberculosis

$M$. avium

M. leprae

M. phlei

M. paratuberculosis

M. avium

M. leprae

M. phlei
$16 S$ rDNA

IGCGGTTEGATCACCTCCTITCTAAGGAGCACCACGAAAA------GCACCCCAACT TGCGGTTGGATCACCTCCTTTCTAAGGAGCACCACGAAAA-----GCACCCCAACT IGCGGCTGGATCACCTCCTITCTAAGGAGCACCACGAAAA-......-.-ACACTCTAAAT TGCGGTTGGATCACCTCCTTTCTAAGGAGCACCTTCAACATGITCCCCCGTGCCCTATAA

GGT--GGGG---IGCG-AGCCGTGAGGGGTTCC--CGTCTGTAGTGGACGGGGGCCGGGI GGT --GGGG---TGCG-AGCCGTGAGGGGTTCC--CGTCTGTAGTGGACGGGGGCCGGGT AGTTTAGGG--- IGTA-AGCCGTCAGGGGTTCT--CATCTGTAGTGGATGAGAGCCGGGT GAGGTAGGGAGTIGCGCGGTTGGGAGAGTCGCCGGCGCCTGIAGTGGTTGTCCGGTGGG

GCGCAACA-_......-GC-1.-- GATTGCCAGACACACT

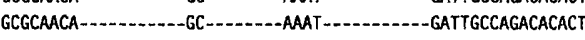

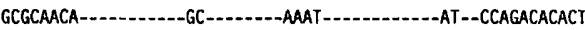
GCACAACAAACGITTGATTGCGGTGGGGAAACACCGTGTCGAGGACTGCCAGACACACT

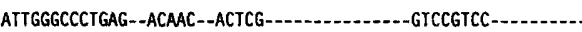
ATTGGGCCCTGAG--ACAAC--ACTCG--.............-GTCCGTCC-........ GTTGGGTCCTGAG--GCAAC--ACTCG-..........-GCTIGATT-.......... AITGGGCTITAAACAACAGCCCGTTCGCCCCCTGGTGTGGGGGTGTGTCCCGGTTGCGGG

-...-GTGTGGAGTCCCTCCATCTTGGTGGTGGGTGTGGTGTTTGAGTAITGGATAGT -..--GTGTGGAGTCCCTCCATCTIGGTGGTGGGGGTGGTGTTTGAGTAJTGGATAGT --.---GGGTGITGTCCCTCATCTTTGGTGGTGGGGTGGGTGITTGAGTATIGGATAGT GTGCCGGTGTGTIGTIGCCCTGCTTTGGTGGTGGGGTGTGGTGTTTGAITCGTGGATAGT

GGTTGCGAGCATCTAGATGAGCGCATGGTC---TCCGTGGC--CGGCGT--ICATCGAAA GGTTGCGAGCATCTAGATGAGCGCATGGTC---TTGGTGGC--CGGCGT--TCATCGAAA GGTTGCGAGCATCTAAATGGATGCGTTGTCAGTTATGTAGTGGTGGCGTAITCATTGAAA GGTTGCGAGCAICT-GATACTTGAGGGCTCCTITTTTTGGGGGTT-CTYGGGTGTTCGAA

235 rONA

-TGTGTAATTTCTTITITAACTCTTGTGTGTMGTMGTGTTTAGGGCGCATGGTGGAI -TGTGTAATTICITTIITAACTCTTGTGTGTAAGTAAGTGTTTAAGGGCGCATGGTGGAT ATGTGTAATTTTCTTCTTIGGTTITGTGTGTAAGTAAGTGCCTAAGGGCGCATGGTGGAT ---TGCAATTTCTTCTGATIITTGTGTTIGTGTGTAAGTGTTTAAGGGGCATGGTGGAT

Fig. 5

Fig. 4. Extended helix 54 of Actinomycetales corresponding to positions 1551-1700 of the multiple sequence alignment of the 235 rDNA sequence. Dashes indicate gaps.

Fig. 5. Sequence alignment of the intergenic spacer region between the $16 \mathrm{~S}$ rDNA and the 235 rDNA gene of mycobacteria. Dashes indicate gaps.

The high sequence variability of the intergenic spacer regions, even between closely related organisms (Liesack et al., 1991; Suzuki et al., 1988), was not observed in $M$. paratuberculosis and $M$. avium. This region comprises $278 \mathrm{bp}$, which is similar in length to the spacer regions of M. bovis BCG (Suzuki et al., 1988), M. tuberculosis 


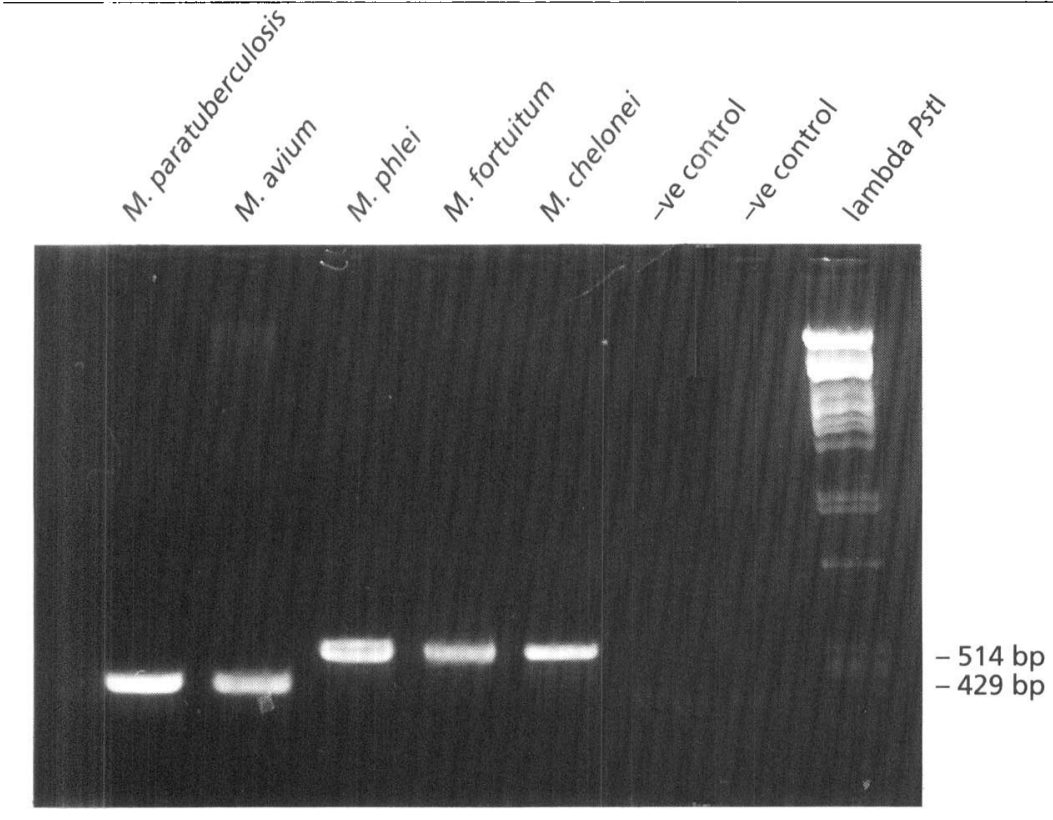

Fig. 6. Agarose gel (1.5\%) electrophoresis of PCR products from the intergenic spacer region of $M$. paratuberculosis, $M$. avium, $M$. phlei, $M$. fortuitum, $M$. chelonei, two negative PCR controls (no template) and lambda Pstl marker.

(Kempsell et al., 1992) and M. leprae (Liesack et al., 1991), and contained only two mismatches between $M$. avium and M. paratuberculosis. Thus, it was not possible to derive specific probes from this region to discriminate between these closely related species. The sequence of the spacer region of $M$. avium serotype 8 is identical to the internal transcribed spacer (ITS) sequences of the MAC strains belonging to the Mav-B sequevar as described by Frothingham \& Wilson (1993). Interestingly, the $M$. paratuberculosis spacer sequence differs in two nucleotides from ITS sequences of the Mav-B sequevar but only in one nucleotide from ITS sequences of the Mav-A sequevar (Frothingham \& Wilson, 1993), both in the same region, and therefore $M$. paratuberculosis seems more related to Mav-A strains based on the spacer region sequences. Considerable differences were found with the rapid growing $M$. phlei. The intergenic spacer region of M. phlei contained several insertions compared to the other mycobacteria increasing the length by $85 \mathrm{bp}$ (Fig. $5)$. This difference was easily demonstrated by comparing the sizes of PCR fragments of this region. The sizes of the intergenic regions of two other fast-growing mycobacteria, $M$. fortuitum and $M$. chelonei, are comparable to that of M. phlei (Fig. 6). Although this insertion has approximately the size of a tRNA and these regions have been shown to encode a tRNA in some rRNA gene clusters (Loughney et al., 1982; Bacot \& Reeves, 1991), no tRNA-encoding region was found in the spacer region of $M$. phlei.

$M$. paratuberculosis and $M$. avium are phylogenetically very closely related, based on small $16 \mathrm{~S}$ rRNA (Stahl \& Urbance, 1990; Rogall et al., 1990), the large 23S rRNA and their intergenic sequences. Although these data and results from other studies indicate that $M$. paratuberculosis and $M$. avium can be considered subspecies (Thorel $e t$ al., 1990), there are nevertheless differences. Most M. paratuberculosis strains grow slower than $M$. avium and are mycobactin dependent in conventional mycobacterial culture media. Only a few $M$. avium strains, including the wood pigeon isolates, now designated $M$. avium subsp. silvaticum (Thorel et al., 1990) are mycobactin dependent. They can cause a disease in cattle which resembles paratuberculosis (Mathews \& McDiarmid, 1979). These strains can be distinguished from $M$. paratuberculosis by a different insertion sequence (IS) (Kunze et al., 1991). IS901 is related to but can be distinguished from IS900, which so far has been found in $M$. paratuberculosis only (McFadden et al., 1987; Green et al., 1989).

In conclusion, the sequences of the $23 \mathrm{~S}$ rDNA of $M$. paratuberculosis and $M$. avium are very similar. These sequences contain only nine mismatches, which none-theless could be used to differentiate these species. In contrast, the $23 \mathrm{~S}$ rDNA sequences of other closely related mycobacteria were less similar than their 16S rRNA/DNA sequences, indicating that $23 \mathrm{~S} r \mathrm{RNA}$ is more suitable for finding differences between related organisms or for deriving specific oligonucleotide probes. The intergenic spacer region between the $16 \mathrm{~S}$ and $23 \mathrm{~S}$ rDNA gene, which has been found to be more diverse among closely related organisms than the rRNA genes themselves, was also almost identical between $M$. paratuberculosis and $M$. avium. The lengths of the intergenic spacers of the fastgrowing mycobacteria are considerably greater than those of the slow-growing mycobacteria, but no tRNAencoding region was found in any of the mycobacterial sequences determined.

\section{ACKNOWLEDGEMENT}

We thank A. Eger and J. Haagsma (Central Veterinary Institute, Lelystad) for providing mycobacterial strains.

\section{REFERENCES}

Armstrong, D. (1985). Treatment of infections in patients with AIDS. Ann Intern Med 103, 738-743. 
Bacot, C. M. \& Reeves, R. H. (1991). Novel tRNA gene organization in the 16S-23S intergenic spacer of the Streptococcus pneumonia rRNA gene cluster. J Bacteriol 173, 4234-4236.

Böddinghaus, B., Wolters, J., Heikens, W. \& Böttger, E. (1990). Phylogenetic analysis and identification of different serovars of Mycobacterium intracellulare at the molecular level. FEMS Microbiol Lett 70, 197-204.

Chiodini, R. J. (1989). Crohn's disease and the mycobacterioses: a review and comparison of two disease entities. Clin Microbiol Rev 2, 90-117.

Devereux, J., Haeberli, P. \& Smithies, O. (1984). A comprehensive set of sequence analysis programs for the VAX. Nucleic Acids Res $12,387-395$.

Felsenstein, J. (1985). Confidence limits on phylogenies: an approach using the bootstrap. Evolution 39, 783-791.

Fitch, W. M. \& Margoliash, E. (1967). Construction of phylogenetic trees. Science 155, 279-284.

Fox, G. E., Wisotzkey, J. D. \& Jurtshuk, P. (1992). How close is close: $16 \mathrm{~S}$ rRNA sequence identity may not be sufficient to guarantee species identity. Int J Syst Bacteriol 42, 166-170.

Frothingham, F. \& Wilson, K. H. (1993). Sequence-based differentiation of strains in the Mycobacterium avium complex. J Bacteriol $\mathbf{1 7 5}$, $2818-2825$

Green, E. P., Tizard, M. L. V., Moss, M. T., Thompson, J., Winterbourne, D. J. \& McFadden, J. J. (1989). Sequence and characteristics of IS900, an insertion element identified in a human Crohn's disease patient of Mycobacterium paratuberculosis. Nucleic Aiids Res 17, 9063-9072.

Gutell, R. R., Schnare, M. N. \& Gray, M. W. (1992). A compilation of large subunit (23S- and 23S-like) ribosomal RNA structures. Nucleic Acids Res 20, 2095-2109.

Higgins, D. G. \& Sharp, P. M. (1988). Clustal: a package for performing multiple sequence alignment on a microcomputer. Gine $73,237-244$.

Höpfl, P., Ludwig, W., Schleiffer, K. H. \& Larsen, N. (1989). The $23 \mathrm{~S}$ ribosomal RNA higher-order structure of Pseudomonas cepaiia and other prokaryotes. Eur J Biocbem 185, 355-364.

Hurley, S. S., Splitter, G. A. \& Welch, R. A. (1988). Deoxyribonucleic acid relatedness of Mycobacterium paratuberculosis to other members of the family Mycobacteriaceae. J Clin Microbiol 38, 143-146.

Kempsell, K. E., Yuan-en, J., Estrada-G, I. C. E., Colston, M. J. \& Cox, R. A. (1993). The nucleotide sequence of the promotor, 165 rRNA and spacer region of the ribosomal RNA operon of Mycobacterium tuberculosis and comparison with Mycobacterium leprae precursor rRNA. J Gen Microbiol 138, 1717-1727.

Kunze, Z. M., Wall, S., Appelberg, R., Silva, M. T., Portaels, F. \& McFadden, J. J. (1991). IS 901 , a new member of a widespread class of atypical insertion sequences, is associated with pathogenicity in Mycobacterium avium. Mol Microbiol 5, 2265-2272.

Liesack, W., Sela, S., Bercovier, H., Pitull, C. \& Stackebrandt, E. (1991). Complete nucleotide sequence of the Mycobacterium leprae $23 \mathrm{~S}$ and $5 \mathrm{~S}$ rRNA genes plus flanking regions and their potential in designing diagnostic oligonucleotide probes. FEBS Lett 281, 114-118.

Loughney, K., Lund, E. \& Dahlberg, J. E. (1982). tRNA genes are found between the $16 \mathrm{~S}$ and $23 \mathrm{~S}$ rRNA genes in Bacillus subtilis. Nucleic Acids Res 10, 1607-1624.

Mathews, P. R. J. \& McDiarmid, A. (1979). The production in bovine calves of a disease resembling paratuberculosis with a Mycobacterium sp. isolated from a wood pigeon (Columbia palumbus L.). Vet $\operatorname{Rec} 104,286$.

McFadden, J. J., Butcher, P. D., Chiodini, R. \& Hermon-Taylor, J. (1987). Crohn's disease-isolated mycobacteria are identical to Mycobacterium paratuberculosis as determined by DNA probes that distinguish between mycobacterial species. J Clin Microbiol 25, 796-801.

McFadden, J. J., Collins, J., Beaman, B., Arthur, M. \& Gitnick, G. (1992). Mycobacteria in Crohn's disease: DNA probes identify the wood pigeon strain of Mycobacterium avium and Mycobacterium paratuberculosis from human tissue. J Clin Microbiol 30, 3070-3073.

Rogall, T., Wolters, J., Flohr, T. \& Böttger, E. C. (1990). Towards a phylogeny and definition of species at the molecular level with the genus Mycobacterium. Int J Syst Bacteriol 40, 323-330.

Roller, C., Ludwig, W. \& Schleiffer, K. H. (1992). Gram-positive bacteria with a high DNA $G+C$ content are characterized by a common insertion within their $23 \mathrm{~S}$ rRNA genes. J Gen Microbiol 138, 1167-1175.

Runyon, E. H., Wayne, L. G. \& Kubica, G. P. (1974). Mycobacteriaceae. In Bergey's Manual of Determinative Bacteriology, 8th edn, pp. 681-701. Edited by R. E. Buchanan \& N. E. Gibbons. Baltimore: Williams \& Wilkins.

Saitou, N. \& Nei, M. (1987). A neighbour-joining method: a new method for constructing phylogenetic trees. Mol Biol Evol 44, 406-425.

Sanger, F., Nicklen, S. \& Coulsen, A. R. (1977). DNA sequencing with chain-terminating inhibitors. Proc Natl Acad Sci USA 85, 3608-3612.

Sneath, P. H. A. \& Sokal, R. R. (1973). Numerical taxonomy. San Francisco: W. H. Freeman.

Stackebrandt, E., Witt, D., Kemmerling, C., Kroppenstedt, R. \& Liesack, W. (1991). Designation of Streptomycete $16 \mathrm{~S}$ and $23 \mathrm{~S}$ rRNA-based target regions for oligonucleotide probes. Appl Environ Microbiol 57, 1468-1477.

Stahl, D. A. \& Urbance, J. W. (1990). The division between fastand slow-growing species corresponds to natural relationships among the mycobacteria. J Bacteriol 172, 116-124.

Suzuki, Y., Nagata, A., Ono, Y. \& Yamada, T. (1988). Complete nucleotide sequence of the 16S rRNA gene of Mycobacterium bovis BCG. J Bacteriol 170, 2886-2889.

Thorel, M. F., Krichevsky, M. \& Vincent Levy-Frebault, V. (1990). Numerical taxonomy of mycobactin-dependent mycobacteria. Emended description of Mycobacterium avium, and description of Mycobacterium avium subsp. avium subsp nov., Mycobacterium avium subsp paratuberculosis subsp nov. and Mycobacterium avium subsp silvaticum subsp nov. I J Syst Bacteriol 40, 254-260.

Van der Giessen, J. W. B., Eger, A., Haagsma, J., Haring, R. M., Gaastra, W. \& Van der Zeijst, B. A. M. (1992). Amplification of $16 S$ rRNA sequences to detect Mycobacterium paratuberculosis. J Med Microbiol 36, 255-263.

Woese, C. R. (1977). Bacterial evolution. Microbiological Rev 51 , 221-271.

Yanisch-Perron, C., Vieira, J. \& Messing, J. (1985). Improved M13 phage cloning vectors and host strains: nucleotide sequences of the M13mp18 and pUC19 vectors. Gene 33, 103-119.

Received 26 August 1993; revised 29 October 1993; accepted 17 November 1993. 